\title{
Effect of mycorrhiza and phosphorus content in nutrient solution on the yield and nutritional status of tomato plants grown on rockwool or coconut coir
}

\author{
Iwona Kowalskaa, Anna Koniecznya, Maciej Gąstołb , Włodzimierz Sadya , Ewa Hanus-Fajerska ${ }^{a}$ \\ anstitute of Plant Biology and Biotechnology and 'Department of Pomology and Apiculture, Faculty of Biotechnology and \\ Horticulture, University of Agriculture in Krakow, 29 Listopada 54, 31-425 Krakow, Poland \\ email: rokowals@cyf-kr.edu.pl
}

\begin{abstract}
Effects of $\mathrm{P}$ level in nutrient solution and the colonization of roots by arbuscular mycorrhizal fungi (AMF) on P uptake by tomato plants, their nutritional status, yield and quality of fruits were studied. Plants were grown on rockwool or coconut coir. Inoculation by a mixture of several AMF species was performed three times during the growing period. The mycorrhizal frequency in roots inoculated with AMF amounted to $35.79-50.82 \%$. The highest level of mycorrhiza was found in plants receiving nutrient solution with a lower concentration of P. Among the experimental factors, only $\mathrm{P}$ level influenced the fruit yield, being higher from plants receiving a nutrient solution with a higher $\mathrm{P}$ level. A higher concentration of $\mathrm{P}$ in nutrient solution imposed better nutritional status of plants. Higher contents of ascorbic acid and total soluble sugars were found in fruits collected from inoculated plants, grown on rockwool.
\end{abstract}

Key words: Solanum lycopersicum L., arbuscular mycorrhizal fungi, soilless culture, plant nutrition, ion uptake

\section{Introduction}

Cultivation of plants under cover has been dominated by soilless cultures, including hydroponics. In this type of cultivation, the plant root system develops in a small volume of growing medium. In such conditions, the root system must be efficient to be able to take up water and nutrients to satisfy the demands of the aboveground parts of the plant which are strongly developed and loaded with fruits, as it is the case in the cultivation of tomatoes and peppers. The need to increase the efficiency of the root system has resulted in the introduction of the cultivation of plants grafted onto rockstock. Arbuscular mycorrhizal fungi (AMF), which live in symbiosis with at least $80 \%$ of all plants on earth (Gianinazzi and Gianinazzi-Pearson 1986), perform similar functions in traditional cultivation and nurseries. Because of a symbiosis with AMF, the plants are better fed and watered, have greater tolerance to soil salinity, as well as thermal and water stresses and are more resistant to pathogenic fungi and nematodes (Al-Karaki 2006). The enhanced nutrient supply to plants in the presence of AMF, results from the increase in the root absorption surface, including the absorption surface of the hyphae, and also from the impact of the fungi on nutrient absorbability by plants (Karandashov and Bucher 2005, Karagiannidis et al. 2007). Additionally, the AMF stimulate the hormones regulating plant growth and increase the rate of photosynthesis (Wu and Zou 2010, Zhu et al. 2014). It has been reported, that the symbiosis of plants with mycorrhizal fungi increases the resistance of plants to stress caused by heavy metals, as a result of increased nutrient availability and synthesis of phytohormones and improved structure of the substrate, which strengthens the plant in harsh environmental conditions (Ryan and Graham 2002, Turnau et al. 2002, Al-Karaki 2006).

The AMF have been tested in the cultivation of the majority of fruit and agricultural plants. In addition, they have become the object of increasing interest in the cultivation of vegetables. The beneficial effect of AMF on plant growth has been proven in the traditional cultivation of tomato, lettuce, onion and hot pepper (Sylvia et al. 2001, Schroeder and Janos 2004). However, the possibility of using AMF in soilless cultures is still an open question. There have been some studies on mycorrhiza in soilless cultures, and their results have indicated the potential of AM fungi to colonize the roots of plants (Al-Karaki 2006, Colla et al. 2008, Dasgan et al. 2008, Cwala et al. 2010).

Dasgan et al. (2008) observed a higher fruit yield from plants colonized by AMF compared to plants not inoculated, regardless of the hydroponic system used. A similar positive effect of inoculation has been observed in studies on peppers (Ikiz et al. 2009) and melons (Rehber 2004) grown in open hydroponic systems. On the other hand, Mueller et al. (2009) showed no effect of AMF on growth and nutrient uptake from nutrient solution in tomatoes grown in sand or peat. These discrepancies are probably caused by the degree of colonization of plant roots by AMF in hydroponic cultures, which is likely limited by the presence of high P concentrations in the root zone of plants (Ryan and Graham 2002, Cwala et al. 2010, Maboko et al. 2013), especially since P is in easily absorbable forms. 
According to Hawkins and George (1997), the conditions for obtaining root colonization by AMF in hydroponic cultivation are low levels of $\mathrm{P}, \mathrm{pH}$ control and good oxygenation of the nutrient solution, whereas in cultures using the substrates such as sowdust or coir, additionally a presence of lignin, phenolics and other organic compounds should be considered. If AMF increase nutrient absorption, including $\mathrm{P}$, it is possible that low level of this macronutrient in the nutrient solution would be beneficial for the fungi themselves, but still supplying enough P for the plant.

The hypothesis of the experiment assumed that via the colonization of the roots of tomatoes grown in soilless culture by AMF, it is possible to reduce $\mathrm{P}$ concentrations in nutrient solution and thereby reach a similar plant nutritional status with this macronutrient, as in the case at the recommended concentration. Since the development of AMF could also be dependent on the physical and biological properties of the root zone, e.g. air content, this hypothesis was verified in the cultivation of tomatoes grown on two types of substrate.

The objective of the study was to determine the effect of two P levels in nutrient solution (15 or $50 \mathrm{mg} \mathrm{dm}^{-3}$ ) and the inoculation of roots by AMF (AMF- or AMF+) on $\mathrm{P}$ uptake by tomato plants and their nutritional status, yield and the quality of fruits. Plants were grown on two different types of substrate, i.e. rockwool or coconut coir.

\section{Material and methods}

\section{Treatments}

A $2 \times 2 \times 2$ factorial design experiment was conducted in the spring-summer of 2012 at the heated foil tunnel belonging to the Faculty of Horticulture, University of Agriculture in Krakow. Tomato plants (Solanum lycopersicum L.) Cv. Admiro $F_{1}$ were grown in six cultivation rows representing two independent sub-blocks with regard to fertigation ( 3 rows $\times 2$ sub-blocks). The treatments were two $\mathrm{P}$ levels in nutrient solution ( $15 \mathrm{or} 50 \mathrm{mg} \mathrm{dm}^{-3}$ ), inoculation of tomato roots by arbuscular mycorrhizal fungi (AMF+ or AMF-) and two different types of substrate, i.e. rockwool or coconut coir.

Throughout the growing season, i.e. from the setting of plants into mats, tomatoes were fed with nutrient solution containing various levels of $\mathrm{P}$, which were introduced to nutrient solution in the form of monopotassium phosphate. The content of other macro and micronutrients as well as the $\mathrm{pH}$ of nutrient solution for all plants were maintained at the same level, and adjusted to the growth stage of plants, e.g. for fruit maturity $\left(\mathrm{mg} \mathrm{dm}^{-3}\right)$, i.e. $\mathrm{N} 180$, K 300, Ca 180, Mg 50, Fe 1.50, Mn 0.6, Zn 0.5, B 0.33, Cu 0.1; pH 5.5 and electrical conductivity (EC) $3.0 \mathrm{mS} \mathrm{cm}^{-1}$.

In each sub-block, half of the plants were inoculated with arbuscular mycorrhizal fungi. Plant inoculation was performed three times by introducing into the growing substrate inoculums containing a mixture of several AMF species. The first inoculation was performed at the time of placing the plants in the holes made in the plastic covering the mat, and the other at two-week intervals (14 days after transplanting [DAT] and 28 DAT). The first inoculation was carried out by spreading $10 \mathrm{~g}$ of the commercial inoculum containing Funneliformis mosseae, Rhizophagus inraradices, Claroideoglomus claroideum, Claroideoglomus etunicatum, G. microaggregatum, Funneliformis geosperum mixed by the producer in proportion as 2:2:1:1:1:1 (720 propagules in $1 \mathrm{~g}$ ) on the mats at the site of cubes with seedlings. Next inoculations were carried out by watering the plants with a commercial inoculum designed for hydroponics (particles less than $256 \mu \mathrm{m}$ ) and containing Funneliformis mosseae, Rhizophagus inraradices, $G$. aggregatum, Claroideoglomus etunicatum, G.deserticola, Rhizophagus clarus, G. monosporum mixed by the producer in proportion as 3:3:3:3:1:1:1:1:1 (160 propagules in 1g). Each plant received $60 \mathrm{~cm}^{3}$ of inoculum suspension in every inoculation. The inoculum suspension was prepared from $25 \mathrm{~g}$ of inoculum suspended in $10 \mathrm{dm}^{3}$ of water.

The cultivation rows, with a length of $21 \mathrm{~m}$, were filled with rockwool (Grotop Master Dry, Grodan ; $100 \times 20 \times$ $7.5 \mathrm{~cm}$ ) or coconut coir (Forteco Profit, Van der Knaap ; $100 \times 20 \times 6 \mathrm{~cm}$ ) mats. Before the start of cultivation, to reduce $\mathrm{EC}$, coconut mats were rinsed with a solution of calcium nitrate and water, until the drainage water EC reached $1.0 \mathrm{mS} \mathrm{cm}^{-1}$.

\section{Plant culture}

Forty-day-old tomato seedlings produced in rockwool cubes $(10 \times 10 \mathrm{~cm})$ were set on the mats next to the holes. Three plants were set on each mat (2.5 plants per $\mathrm{m}^{2}$ ). There were 36 plants in each variant of the experiment (12 plants $\times 3$ repetitions). In addition, in each variant of the experiment there were 9 plants ( 3 plants $\times 3$ repetitions) removed at 82 DAT to determine the level of colonization. 
Plants were inserted into the holes in the mats after 10 days, i.e. at the stage when $50 \%$ of the flowers in the first cluster had blossomed. In the early period of cultivation (for 10 days), fertigation was carried out with $100-200$ $\mathrm{cm}^{3}$ of nutrient solution supplied once every one or two days. In the subsequent periods of plant growth, the frequency and amount of the supplied nutrient solution were estimated on the basis of mat moisture and the size of radiation. The evaluation of rockwool mat moisture was done using a WCM (Grodan ${ }^{\circ}$ ) meter, while evaluation of the coconut mats used the gravimetric method. The fertigation of plants was done using an open system, i.e. without recirculation of nutrient solution. $\mathrm{EC}$ and $\mathrm{pH}$ control in drainage water collected from both types of mats and extract taken from the mats of rockwool were conducted regularly. The composition of the nutrient solution was adjusted to the growth stage of plants and external conditions (temperature and radiation). Plants were pruned to a single stem only. The growing point of the main stem was removed and leaving two leaves above the seventh cluster. All typical nursing treatments were carried out in accordance with generally accepted principles for the soilless cultivation of tomatoes. Protection of plants against pests (greenhouse whitefly, aphids) was controlled using natural entomophages. Plants were pollinated by bumblebees.

\title{
Observations and measurements
}

\author{
Mycorrhizal colonization
}

The evaluation of plant colonization by AMF was carried out over two time periods, i.e. in the phase of growing fruit on the VI cluster (82 DAT; 1. period) and at the end of cultivation (112 DAT; 2. period). Three whole root balls were collected from each repetition of particular variants of the experiment to estimate the level of colonization. The aboveground part of the plant was cut down, and then one-third of the mat occupied by the plant was cut off. $5 \mathrm{~g}$ samples were collected from the isolated root system and microscope slides were prepared from this material according to a modified Phillips and Hayman (1970) method. Collected roots were cold macerated in a solution of $10 \% \mathrm{KOH}$. After rinsing in water, they were acidified with $5 \%$ lactic acid $(24 \mathrm{~h})$ and then stained using a $0.03 \%$ solution of trypan blue dissolved in a mixture of lactic acid, glycerol and water (v/v/v 1:1:1). Roots were cut into $1 \mathrm{~cm}$ pieces, from which the microscopic slides were prepared. They were encapsulated with a mixture of glycerol and lactic acid ( $v / v 5: 1$ ). Each examined plant was represented by 90 pieces of roots, each having a length of $1 \mathrm{~cm}$. The evaluation of the colonization of the roots by arbuscular mycorrhizal fungi was made according to the Trouvelot et al. (1986) method.

Mycorrhizal frequency (F\%) and relative intensity of mycorrhiza (M\%), and relative abundance of arbuscule (A\%) were assessed in each root segment. The mycorrhizal parameters were calculated using Mycocalc software (http:// www.dijon.inra.fr/mychintec/Mycocalc-prg/download.html). Observation of the level of mycorrhizal colonization was made using an Axio Imager N2 (Carl Zeiss) with Nomarski contrast.

\section{Leaf and fruit analyses}

The analysis of leaves at the stage of fruit at the VII cluster of $3-4 \mathrm{~cm}$ in diameter was performed in order to determine the nutritional status of plants. The fully-developed fourth leaf from the growing point was collected for mineral analysis. Tomato leaves were dried at $70^{\circ} \mathrm{C}$ for $48 \mathrm{~h}$ in a laboratory dryer with forced air circulation. Dried samples were ground in a Pulverisette 14 variable speed rotor mill (FRITSCH) using a $0.5 \mathrm{~mm}$ sieve. The levels of $\mathrm{P}, \mathrm{K}, \mathrm{Ca}, \mathrm{Mg}, \mathrm{S}, \mathrm{B}, \mathrm{Cu}, \mathrm{Fe}, \mathrm{Mn}, \mathrm{Mo}$ and $\mathrm{Zn}$ in leaf samples were determined after mineralization in $65 \%$ extra pure $\mathrm{HNO}_{3}$ in a CEM MARS-5 Xpress microwave system (Pasławski and Migaszewski 2006). The content of minerals was determined using an ICP-OES high-dispersion spectrometer (Inductively Coupled Plasma Optical Emission Spectrometry) Prodigy Teledyne Leeman Labs. Leaf N content was assayed by the Kjeldahl method using a VELP Scientifica UDK 193 distillation unit (Persson and Wennerholm 1999). Mineral composition was expressed on a dry mass basis, which was estimated using the dryer method to constant weight.

Fruits of the II - III cluster, aligned in terms of size and uniformly stained, were subjected to chemical analysis. Ten pieces of fruit from each repetition were selected for analysis and homogenized. The following parameters were estimated: dry matter $\left(70^{\circ} \mathrm{C}\right)$, ascorbic acid using Tillmans method (Krełowska-Kułas 1993), total soluble sugars using the anthrone method (Yemm and Wills 1954) and acidity (Pijanowski et al. 1973). 


\section{Fruit yield}

Fruits were harvested weekly at the breaker stage. The first collection of fruits was performed in 61 DAT. Yield data were collected from twelve plants per repetition for each variant of the experiment, and the total, marketable and unmarketable yields were calculated. Fruits were regarded as unmarketable when they exhibited cracking, zippering, rotting, blossom-end rot, rain-check or fell into the extra small category (less than $40 \mathrm{~mm}$ fruit diameter). Tomato yield was expressed as $\mathrm{kg} \mathrm{m}^{-2}$.

\section{Statistical analysis}

Data was subjected to the three-way analysis of variance using the ANOVA module of Statistica 10.0 PL (Statsoft, Inc.). In the analysis of interactions, to determine the significance of differences between means the Tukey test was used. Significance was declared at $p<0.05$

\section{Results}

\section{AMF root colonization}

The effectiveness of inoculation was proved in both periods of assessing the degree of tomato root colonization by AMF. Mycorrhizal frequency (F) in 1. period of the assessment, i.e. after 82 DAT was $35.79 \%$ and $1.20 \%$ in AMF+ and AMF- plants, respectively (Table 1). The level of root colonization at the end of cultivation, i.e. after 112 DAT, was higher, and amounted to $50.82 \%$ and $3.05 \%$, in AMF+ and AMF- plants respectively. Experimental factors and their interactions had a significant effect on mycorrhizal frequency. Relative intensity of mycorrhiza (M) in inoculated plants was 6.10 and $10.43 \%$, in 1 . and 2. period of roots isolation, respectively. Relative abundance of arbuscule (A) was 1.01 and $2.51 \%$, respectively. In non-inoculated plants $M$ and A values were close to zero.

Table 1. Effect of phosphorus level in nutrient solution $\left(\mathrm{mg} \mathrm{dm}^{-3}\right)$, mycorrhiza and type of substrate on mycorrhizal frequency (F\%), relative intensity of mycorrhiza ( $\mathrm{M} \%$ ) and relative abundance of arbuscule $(\mathrm{A} \%)$ in roots of tomato plants.

\begin{tabular}{|c|c|c|c|c|c|c|}
\hline \multirow{2}{*}{ Treatment } & $\mathrm{F}$ & $M$ & $A$ & $\mathrm{~F}$ & $M$ & $A$ \\
\hline & \multicolumn{3}{|c|}{ 1. period } & \multicolumn{3}{|c|}{ 2. period } \\
\hline \multicolumn{7}{|l|}{ Phosphorus } \\
\hline 15 & $16.90 \pm 1.91$ & $3.19 \pm 0.50$ & $0.82 \pm 0.18$ & $18.50 \pm 2.52$ & $3.91 \pm 0.72$ & $1.34 \pm 0.33$ \\
\hline \multirow[t]{2}{*}{50} & $15.23 \pm 1.62$ & $2.30 \pm 0.35$ & $0.01 \pm 0.04$ & $12.84 \pm 1.73$ & $1.76 \pm 0.37$ & $0.06 \pm 0.04$ \\
\hline & n.s. & n.s. & $*$ & $*$ & $*$ & $*$ \\
\hline \multicolumn{7}{|l|}{ Mycorrhiza } \\
\hline AMF- & $1.20 \pm 0.19$ & $0.19 \pm 0.07$ & $0.02 \pm 0.01$ & $3.05 \pm 0.34$ & $0.12 \pm 0.04$ & $0.07 \pm 0.04$ \\
\hline \multirow[t]{2}{*}{ AMF+ } & $35.79 \pm 2.03$ & $6.10 \pm 0.06$ & $1.01 \pm 0.20$ & $50.82 \pm 3.40$ & $10.43 \pm 1.20$ & $2.51 \pm 0.61$ \\
\hline & $*$ & $*$ & $*$ & $*$ & $*$ & $*$ \\
\hline \multicolumn{7}{|l|}{ Substrate } \\
\hline Coconut & $18.28 \pm 1.89$ & $3.40 \pm 0.49$ & $0.69 \pm 0.26$ & $14.85 \pm 2.01$ & $2.63 \pm 0.47$ & $0.53 \pm 0.15$ \\
\hline \multirow[t]{2}{*}{ Rockwool } & $13.70 \pm 1.58$ & $2.02 \pm 0.34$ & $0.18 \pm 0.05$ & $16.64 \pm 2.36$ & $3.09 \pm 0.69$ & $0.90 \pm 0.32$ \\
\hline & $*$ & $*$ & $*$ & n.s. & n.s & n.s \\
\hline
\end{tabular}

In the first period of assessment of the colonization level, the highest percentage of mycorrhizal frequency was estimated in inoculated plants isolated from coconut and receiving nutrient solution with a concentration of P 15 $\mathrm{mg} \mathrm{dm}^{-3}$ (Fig. 1). On the other hand, a significantly lower mycorrhizal frequency was estimated both in the roots of plants receiving the same nutrient solution but growing on rockwool and in the roots of plants growing on coconut and receiving nutrient solution with the standard concentration of P, i.e. $50 \mathrm{mg} \mathrm{dm}^{-3}$. In these variants of the experiment the mycorrhizal frequency was at the same level. The lowest mycorrhizal frequency was estimated in roots of plants isolated from rockwool and receiving nutrient solution with $50 \mathrm{mg} \mathrm{dm}^{-3}$ of $P$. A different effect of experimental factor interactions on mycorrhizal frequency was proved in the second period of isolation (Fig. 2). In this period of isolation, the highest mycorrhizal frequency was estimated in roots of plants growing on rock- 
wool and, similar to the first period of isolation, receiving a nutrient solution with a phosphorus content of $15 \mathrm{mg}$ $\mathrm{dm}^{-3}$. Plants receiving a nutrient solution with an analogous concentration of phosphorus, but growing on coconut were colonized by AMF to a much lower degree. Mycorrhizal frequency at the similar level was estimated in plants growing on rockwool and receiving nutrient solution with the standard concentration of $P\left(50 \mathrm{mg} \mathrm{dm}^{-3}\right)$. In this period, the lowest mycorrhizal frequency was estimated in roots of plants growing on coconut and receiving nutrient solution with a concentration of $\mathrm{P} 50 \mathrm{mg} \mathrm{P} \mathrm{dm}^{-3}$.

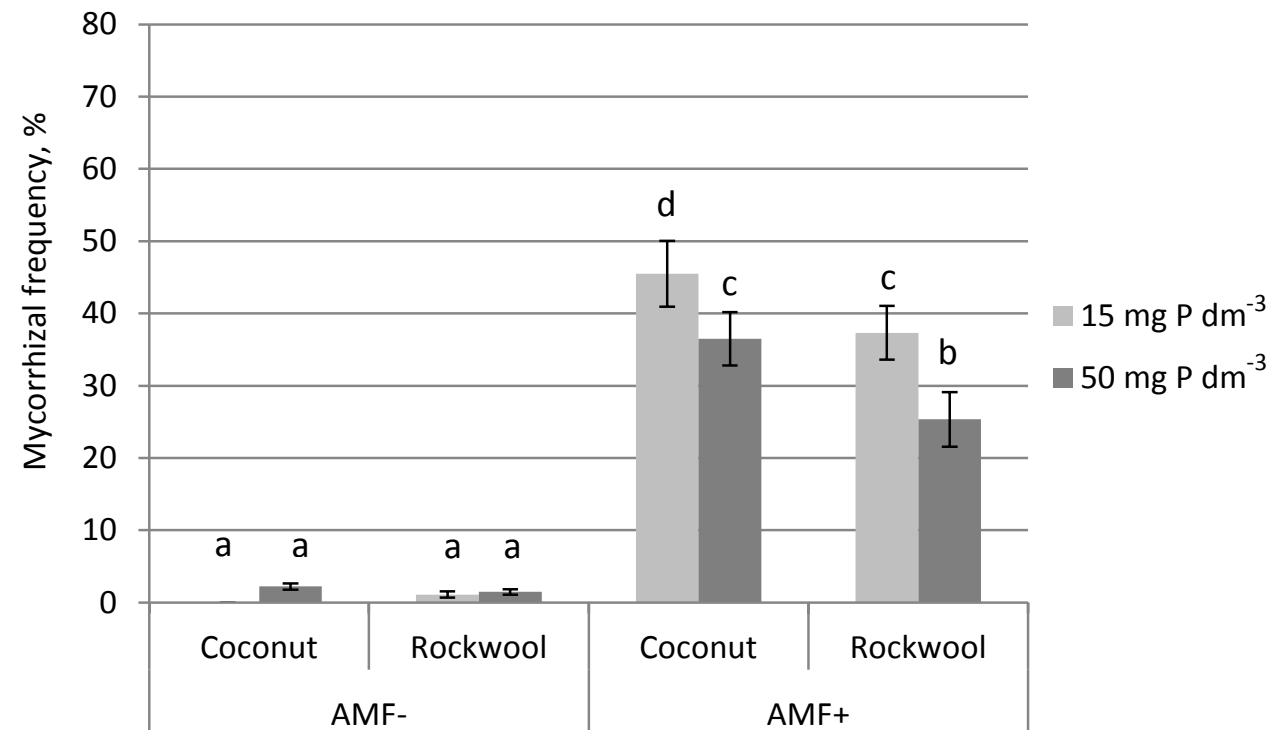

Fig. 1. Interaction between phosphorus level in nutrient solution, mycorrhiza and type of substrate on mycorrhizal frequency in roots of tomato plants; 1 . period of isolation (82 days after transplanting (DAT))

Means followed by different letters differ at $p<0.05$.; bars indicate standard error

AMF-/AMF+-non-inoculated plants by arbuscular mycorrhizal fungi (AMF)/inoculated plants by AMF

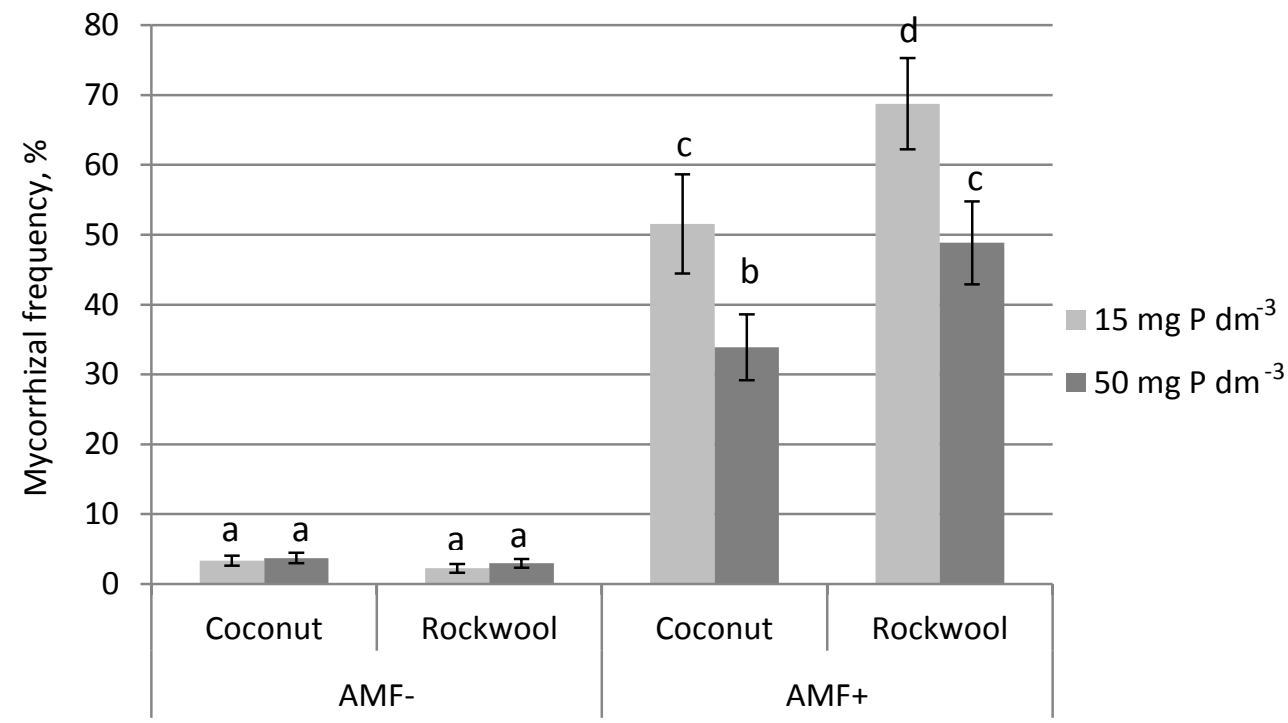

Fig. 2. Interaction between phosphorus level in nutrient solution, mycorrhiza and type of substrate on mycorrhizal frequency in roots of tomato plants; 2 . period of isolation (112 days after transplanting (DAT))

Means followed by different letters differ at $p<0.05$; ; bars indicate standard error

AMF-/AMF+ - non-inoculated plants by arbuscular mycorrhizal fungi (AMF)/inoculated plants by AMF 


\section{Yield}

Among the experimental factors, only the level of phosphorus had an influence on the total and marketable yield of tomato plants (Table 2). A significantly higher total and marketable yield was harvested from plants receiving a nutrient solution with a higher concentration of phosphorus, i.e. $50 \mathrm{mg} \mathrm{dm}^{-3}$ (1.97 and $2.37 \mathrm{~kg} \mathrm{~m}^{-2}$, respectively) in comparison to plants receiving a nutrient solution with a concentration of $P 15 \mathrm{mg} \mathrm{dm}^{-3}$. The interactions between experimental factors did not have any significant effect on yield. Unmarketable yield of plants receiving a nutrient solution containing $15 \mathrm{mg} \mathrm{dm}^{-3}$ of $\mathrm{P}$, amounted to $0.68 \mathrm{~kg} \mathrm{~m}^{-2}$ and it was 2.5 times greater than in $50 \mathrm{mg}$ $\mathrm{dm}^{-3}$ of $\mathrm{P}$ in nutrient solution.

Table 2. The effect of phosphorus level in nutrient solution $\left(\mathrm{mg} \mathrm{dm}^{-3}\right)$, mycorrhiza, and type of substrate on yield of tomato fruits $\left(\mathrm{kg} \mathrm{m}^{-2}\right)$.

\begin{tabular}{ccc}
\hline Treatment & Total yield & Marketable yield \\
\hline Phosphorus level & & \\
15 & $18.64 \pm 0.34$ & $17.96 \pm 0.38$ \\
50 & $20.61 \pm 0.22$ & $20.33 \pm 0.29$ \\
& $*$ & $*$ \\
Mycorrhiza & $19.70 \pm 0.36$ & $19.27 \pm 0.44$ \\
AMF- & $19.54 \pm 0.45$ & $19.02 \pm 0.54$ \\
AMF+ & n.s. & n.s. \\
& & $19.39 \pm 0.48$ \\
Substrate & $19.63 \pm 0.44$ & $18.90 \pm 0.49$ \\
Coconut & $19.61 \pm 0.37$ & n.s. \\
Rockwool & n.s. & \\
&
\end{tabular}

\section{Fruit quality}

The level of phosphorus, regardless of any other experimental factors, had a significant effect on the content of dry matter, ascorbic acid and amino acids in fruits (Table 3). Fruits harvested from plants receiving a nutrient solution with a standard concentration of $\mathrm{P}$ were characterized by lower concentrations of these parameters.

Table 3. The effect of phosphorus level in nutrient solution $\left(\mathrm{mg} \mathrm{dm}^{-3}\right)$, mycorrhiza and type of substrate on quality of tomato fruits.

\begin{tabular}{cccccc}
\hline Treatment & Dry matter, \% & $\begin{array}{c}\text { Ascorbic acid, } \\
\mathrm{mg} 100 \mathrm{~g}^{-1} \mathrm{f} . \mathrm{m} .\end{array}$ & $\begin{array}{c}\text { Total soluble } \\
\text { sugars, } \% \\
\text { f.m. }\end{array}$ & $\begin{array}{c}\text { Amino acid, } \\
\mathrm{mg} 100^{-1} \mathrm{~g} \\
\text { f.m. }\end{array}$ & $\begin{array}{c}\text { Titratable acidity, } \\
\% \text { f.m. }\end{array}$ \\
\hline $\begin{array}{c}\text { Phosphorus } \\
\text { level }\end{array}$ & & & & & \\
15 & $5.81 \pm 0.03$ & $11.28 \pm 0.42$ & $2.36 \pm 0.07$ & $68.01 \pm 1.74$ & $0.70 \pm 0.01$ \\
50 & $5.61 \pm 0.06$ & $10.00 \pm 0.23$ & $2.36 \pm 0.04$ & $61.98 \pm 1.53$ & $0.70 \pm 0.01$ \\
& $*$ & $*$ & n.s. & $*$ & n.s. \\
\hline Mycorrhiza & & & & & \\
AMF- & $5.67 \pm 0.05$ & $10.18 \pm 0.21$ & $2.29 \pm 0.04$ & $65.99 \pm 2.07$ & $0.69 \pm 0.01$ \\
AMF+ & $5.74 \pm 0.06$ & $11.10 \pm 0.47$ & $2.44 \pm 0.07$ & $63.99 \pm 1.61$ & $0.70 \pm 0.01$ \\
& n.s. & $*$ & $*$ & n.s. & n.s. \\
\hline Substrate & & & & & \\
Coconut & $5.71 \pm 0.05$ & $10.48 \pm 0.26$ & $2.26 \pm 0.03$ & $64.27 \pm 1.44$ & $0.70 \pm 0.01$ \\
Rockwool & $5.70 \pm 0.06$ & $10.80 \pm 0.48$ & $2.47 \pm 0.06$ & $65.72 \pm 2.21$ & $0.69 \pm 0.01$ \\
& n.s. & n.s. & $*$ & n.s. & n.s. \\
\hline
\end{tabular}

* means are significantly different; n.s. - differences are not significant; \pm - standard error AMF-/AMF+ - non-inoculated plants by arbuscular mycorrhizal fungi (AMF)/inoculated plants by AMF f.m. - fresh matter 
The effect of interactions between the level of $\mathrm{P}$ in a nutrient solution and the presence of AMF on the content of dry matter and ascorbic acid (Fig. 3 and 4) was also demonstrated.

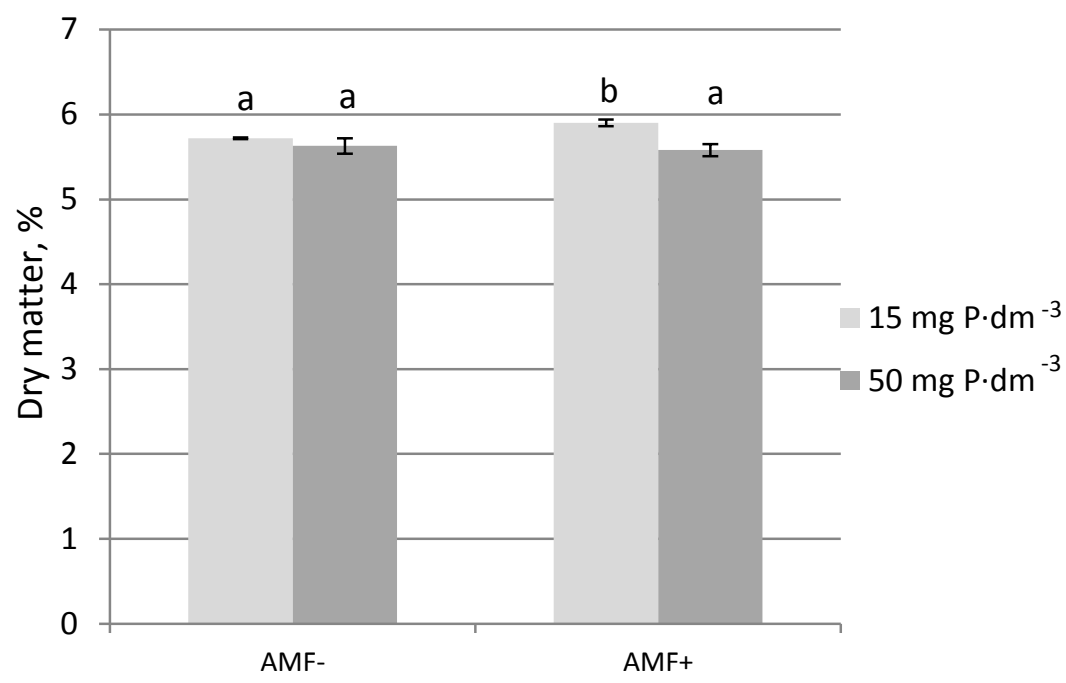

Fig. 3. Interaction between phosphorus level in nutrient solution and mycorrhiza on dry matter content in tomato fruits

Means followed by different letters differ at $p<0.05$.; bars indicate standard error

AMF-/AMF+ - non-inoculated plants by arbuscular mycorrhizal fungi (AMF)/inoculated plants by AMF

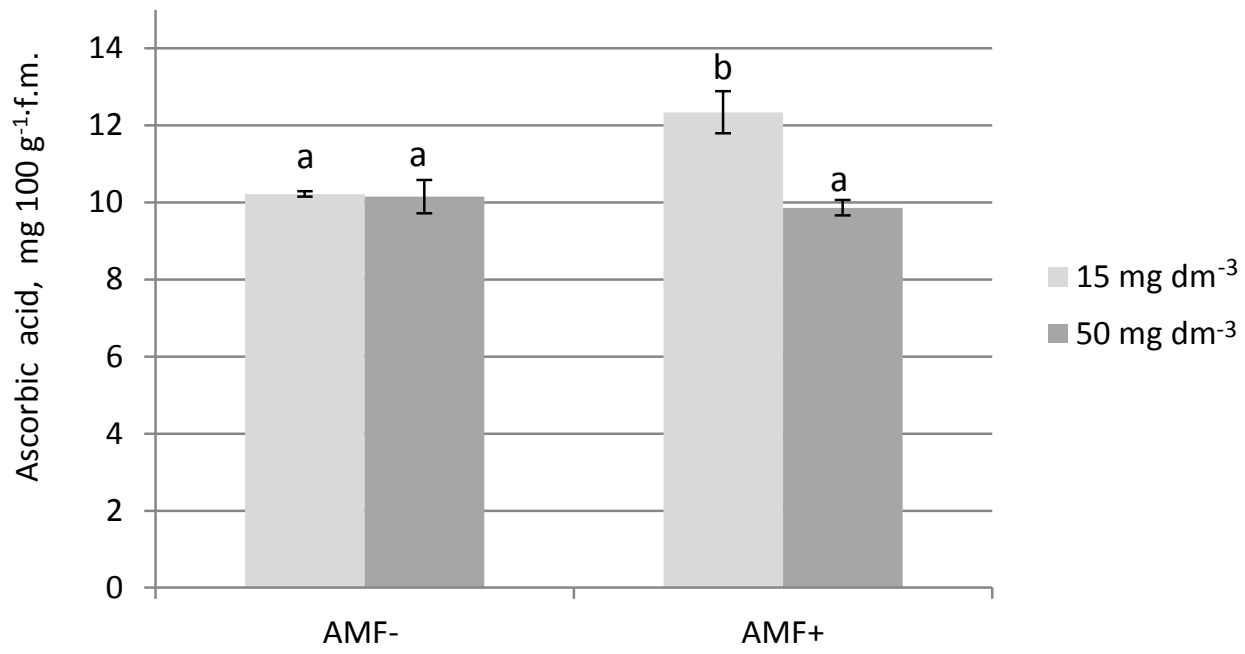

Fig. 4. Interaction between phosphorus level in nutrient solution and mycorrhiza on ascorbic acid content in tomato fruits

Means followed by different letters differ at $p<0.05$.; bars indicate standard error AMF-/AMF+-non-inoculated plants by arbuscular mycorrhizal fungi (AMF)/inoculated plants by AMF f.m. - fresh matter

Significantly higher concentrations of these parameters were estimated in fruits collected from plants receiving a nutrient solution with a lower concentration of $\mathrm{P}$ and at the same time inoculated with AMF. Non-inoculated plants receiving a nutrient solution with various concentrations of $\mathrm{P}$ did not differ in the contents of dry matter and ascorbic acid.

Inoculation of tomato roots with AMF, regardless of any other experimental factors, had an effect on the content of ascorbic acid and total soluble sugars in tomato fruits (Table 3). Higher values for these parameters were estimated in fruits collected from plants inoculated with AMF. 
Analysis of the effect of the significant interaction between inoculation with AMF and the type of substrate on content of ascorbic acid and total soluble sugars proved that inoculation of plants only had an influence on higher levels of these parameters in fruits collected from plants grown on rockwool (Table 4).

Table 4. Effect of interaction between mycorrhiza and type of substrate on ascorbic acid and total soluble sugars content in tomato fruits.

\begin{tabular}{|c|c|c|c|}
\hline Mycorrhiza & Substrate & 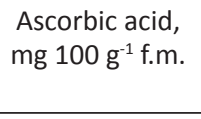 & $\begin{array}{l}\text { Total soluble } \\
\text { sugars, } \% \\
\text { f.m. }\end{array}$ \\
\hline \multirow[t]{2}{*}{ AMF- } & Coconut & $10.46 \pm 0.27^{a}$ & $2.27 \pm 0.05^{\mathrm{a}}$ \\
\hline & Rockwool & $9.90 \pm 0.29^{\mathrm{a}}$ & $2.31 \pm 0.05^{a}$ \\
\hline \multirow[t]{2}{*}{ AMF+ } & Coconut & $10.49 \pm 0.48^{\mathrm{a}}$ & $2.25 \pm 0.04^{a}$ \\
\hline & Rockwool & $11.72 \pm 0.76^{b}$ & $2.62 \pm 0.07^{b}$ \\
\hline
\end{tabular}

means followed by the same letters are not significantly different at $p<0.05$; \pm - standard error; AMF-/AMF+ - non-inoculated plants by arbuscular mycorrhizal fungi (AMF)/inoculated plants by AMF f.m. - fresh matter

The type of substrate, regardless of any other experimental factors, had an influence on the content of total soluble sugars, a higher concentration of which was estimated in fruits harvested from plants grown on rockwool compared to fruits from plants grown on coconut coir (Table 3).

\section{Nutritional status of plants}

Mainly the level of phosphorus in a nutrient solution had an impact on the nutritional status of plants, and this significantly differentiated the content of $\mathrm{P}, \mathrm{K}, \mathrm{Ca}, \mathrm{Fe}, \mathrm{B}$ and dry matter in tomato leaves (Table 5 and 6 ). A higher concentration of $\mathrm{P}$ in a nutrient solution influenced a better nutritional status in terms of $\mathrm{Ca}$ and $\mathrm{P}$, whereas the content of $\mathrm{K}, \mathrm{Fe}, \mathrm{B}$ and dry matter in leaves was lower. Inoculation of plants with AMF had only an influence on the content of $\mathrm{Cu}$ and $\mathrm{Zn}$. Inoculated plants were characterized by lower concentrations of these micronutrients. The type of substrate, regardless of other experimental factors, had a significant effect on the content of $\mathrm{Cu}$ and Mo.

Table 5. Effect of phosphorus level in the nutrient solution $\left(\mathrm{mg} \mathrm{dm}^{-3}\right)$, mycorrhiza and type of substrate on dry matter (DM) and macroelements content in tomato leaves (\% dry matter).

\begin{tabular}{|c|c|c|c|c|c|c|}
\hline Treatment & DM, \% & $\mathrm{N}$ & $P$ & $\mathrm{~K}$ & $\mathrm{Ca}$ & $\mathrm{Mg}$ \\
\hline \multicolumn{7}{|l|}{$\begin{array}{l}\text { Phosphorus } \\
\text { level }\end{array}$} \\
\hline 15 & $13.71 \pm 0.20$ & $3.08 \pm 0.03$ & $0.24 \pm 0.01$ & $2.87 \pm 0.04$ & $4.19 \pm 0.05$ & $0.73 \pm 0.03$ \\
\hline \multirow[t]{2}{*}{50} & $12.89 \pm 0.17$ & $3.07 \pm 0.04$ & $0.77 \pm 0.02$ & $2.73 \pm 0.04$ & $4.68 \pm 0.15$ & $0.77 \pm 0.03$ \\
\hline & $*$ & n.s. & $*$ & $*$ & $*$ & n.s. \\
\hline \multicolumn{7}{|l|}{ Mycorrhiza } \\
\hline AMF- & $13.31 \pm 0.11$ & $3.08 \pm 0.02$ & $0.51 \pm 0.08$ & $2.82 \pm 0.05$ & $4.39 \pm 0.12$ & $0.76 \pm 0.03$ \\
\hline \multirow[t]{2}{*}{ AMF+ } & $13.29 \pm 0.30$ & $3.07 \pm 0.04$ & $0.50 \pm 0.08$ & $2.78 \pm 0.05$ & $4.48 \pm 0.15$ & $0.74 \pm 0.03$ \\
\hline & n.s. & n.s. & n.s. & n.s. & n.s. & n.s. \\
\hline \multicolumn{7}{|l|}{ Substrate } \\
\hline Coconut & $13.18 \pm 0.26$ & $3.09 \pm 0.03$ & $0.52 \pm 0.09$ & $2.77 \pm 0.05$ & $4.55 \pm 0.14$ & $0.75 \pm 0.03$ \\
\hline \multirow[t]{2}{*}{ Rockwool } & $13.42 \pm 0.17$ & $3.06 \pm 0.03$ & $0.49 \pm 0.08$ & $2.82 \pm 0.04$ & $4.32 \pm 0.12$ & $0.74 \pm 0.03$ \\
\hline & n.s. & n.s. & n.s. & n.s. & n.s. & n.s. \\
\hline
\end{tabular}


Table 6. Effect of phosphorus level in the nutrient solution $\left(\mathrm{mg} \mathrm{dm}^{-3}\right)$, mycorrhiza and type of substrate on microelements content in tomato leaves ( $\mathrm{mg} \mathrm{kg}^{-1} \mathrm{dry}_{\text {matter}) \text {. }}$

\begin{tabular}{ccccccc}
\hline Treatment & Fe & Cu & Zn & Mn & Mo & B \\
\hline $\begin{array}{c}\text { Phosphorus } \\
\text { level }\end{array}$ & & & & & & \\
15 & $175.35 \pm 7.52$ & $9.52 \pm 0.41$ & $24.78 \pm 0.92$ & $248.78 \pm 7.39$ & $3.45 \pm 0.17$ & $50.38 \pm 1.11$ \\
50 & $153.24 \pm 4.92$ & $8.74 \pm 0.46$ & $24.89 \pm 0.65$ & $229.02 \pm 5.53$ & $3.58 \pm 0.32$ & $47.08 \pm 1.02$ \\
& $*$ & n.s. & n.s. & n.s. & n.s. & $*$ \\
Mycorrhiza & & & & & & \\
AMF- & $161.31 \pm 5.14$ & $9.78 \pm 0.40$ & $26.23 \pm 0.46$ & $243.03 \pm 6.77$ & $3.40 \pm 0.26$ & $49.51 \pm 1.33$ \\
AMF+ & $167.27 \pm 6.65$ & $8.48 \pm 0.41$ & $23.44 \pm 0.84$ & $234.78 \pm 7.35$ & $3.63 \pm 0.24$ & $47.95 \pm 0.95$ \\
& n.s. & $*$ & $*$ & n.s. & n.s. & n.s. \\
Substrate & & & & & & \\
Coconut & $166.80 \pm 8.01$ & $9.84 \pm 0.34$ & $24.14 \pm 0.81$ & $243.38 \pm 6.71$ & $2.77 \pm 0.09$ & $47.79 \pm 0.92$ \\
Rockwool & $161.78 \pm 6.13$ & $8.42 \pm 0.44$ & $25.53 \pm 0.73$ & $234.43 \pm 7.36$ & $4.26 \pm 0.13$ & $49.67 \pm 1.33$ \\
& n.s. & $*$ & n.s. & n.s. & $*$ & n.s. \\
\hline
\end{tabular}

* means are significantly different; n.s. - differences are not significant; \pm - standard error

AMF-/AMF+ - non-inoculated plants by arbuscular mycorrhizal fungi (AMF)/inoculated plants by AMF

Regardless of inoculation with AMF or the lack of it, plants grown on rockwool and receiving a nutrient solution with a concentration of P 15 or $50 \mathrm{mg} \mathrm{dm}^{-3}$ accumulated a similar content of K, i.e. $2.82-2.84 \%$ d.m. (Fig. 5).

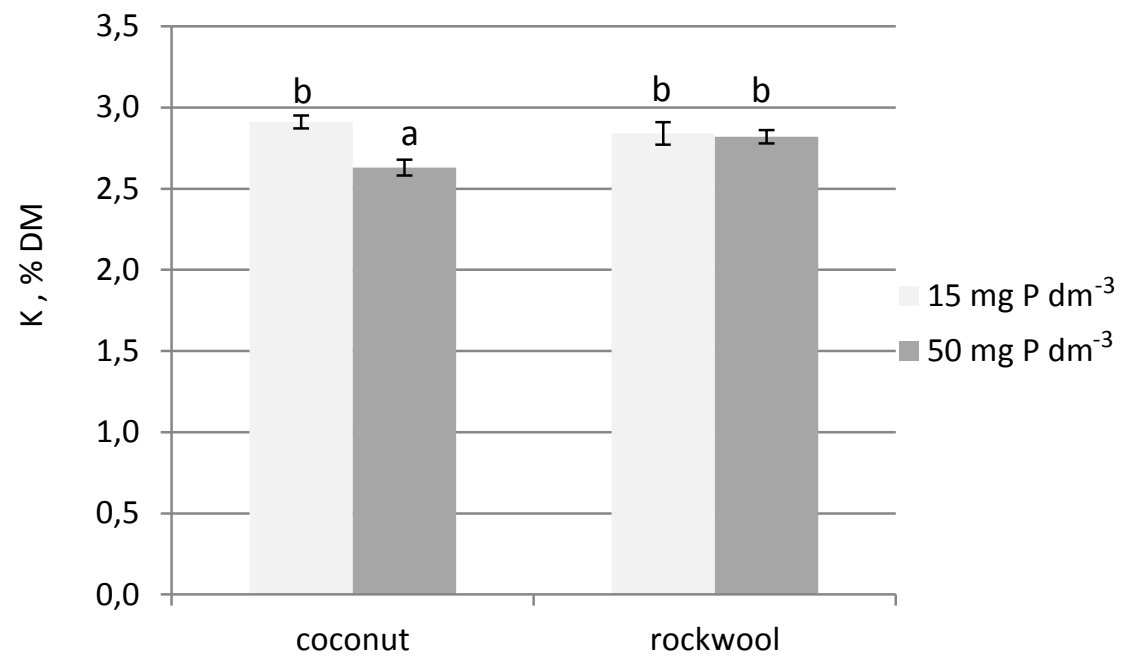

Fig. 5. Interaction between phosphorus level in nutrient solution and type of substrate on $\mathrm{K}$ content in tomato leaves. Means followed by the same letters are not significantly different at $p<0.05$; bars indicate standard error. AMF-/AMF+ - non-inoculated plants by arbuscular mycorrhizal fungi (AMF)/inoculated plants by AMF

DM - dry matter

However, in cultivation on coconut, the level of phosphorus in a nutrient solution had a significant impact on the content of $\mathrm{K}$ in leaves. A lower content of $\mathrm{K}$ was estimated in leaves from plants receiving a standard concentration of $\mathrm{P}$ in nutrient solution (50 $\mathrm{mg} \mathrm{P} \mathrm{dm}^{-3}$ ) compared to leaves collected from plants receiving a nutrient solution with $15 \mathrm{mg} \mathrm{P} \mathrm{dm}^{-3}$. The significant effect of interactions between the level of $\mathrm{P}$ in a nutrient solution and the type of substrate on the content of Mo indicated that the level of P did not differentiate the Mo content in the leaves of tomato plants grown on coconut coir, while in the cultivation on rockwool, a higher concentration of $P$ in nutrient solution had an impact on the accumulation of significantly more Mo in the leaves than in plants fed the nutrient solution containing $15 \mathrm{mg} \mathrm{dm}^{-3}$ of $\mathrm{P}$ (Fig. 6). 


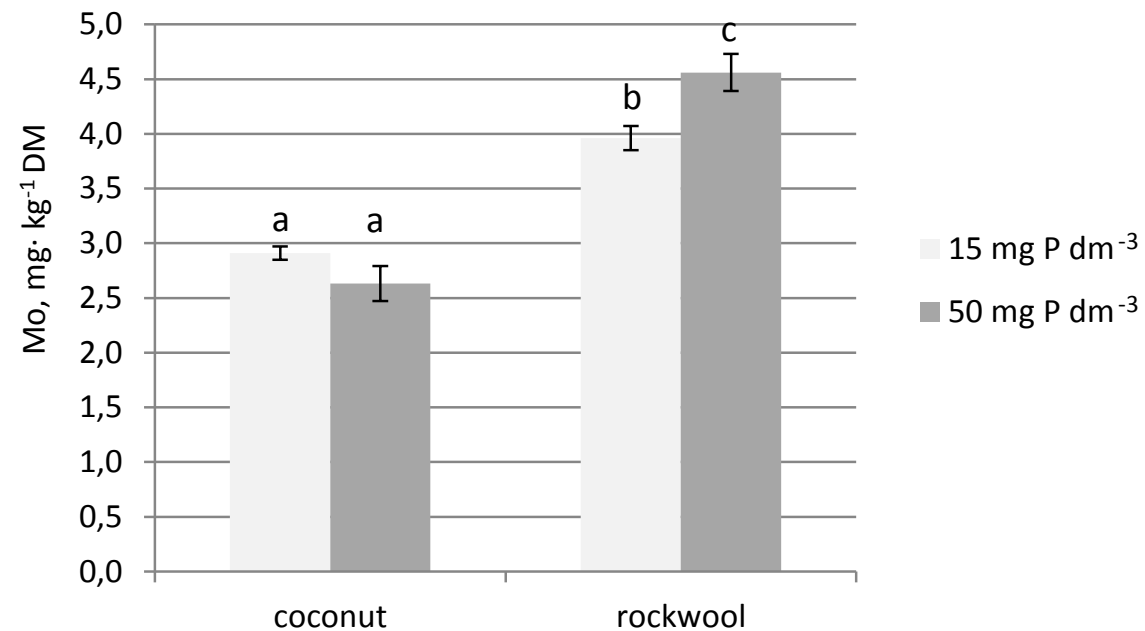

Fig. 6. Interaction between phosphorus level in nutrient solution and type of substrate on Mo content in tomato leaves

Means followed by the same letters are not significantly different at $p<0.05$; bars indicate standard error

AMF-/AMF+ - non-inoculated plants by arbuscular mycorrhizal fungi (AMF)/inoculated plants by AMF

DM - dry matter

\section{Discussion}

Mineral soils are the natural habitat of AMF (Brundrett 1991). Opinions on the possibility of colonization of growing media in soilless cultures by AMF are diverse. Al-Karaki (2006), Colla et al. (2008), Dasgan et al. (2008), Cwala et al. (2010), and Maboko et al. (2013) suggested the possibility of the colonization of plant roots by AMF in cultivation on perlite, peat soil, coir, and sawdust. The benefits of the successful colonization of soilless cultures seem to even surpass those achievable in traditional cultivation, because in soilless cultures the aim is to obtain strongly developed root systems, due to the small volume of substrate per plant $\left(4-5 \mathrm{dm}^{3}\right)$, while simultaneously plants have to take up large amounts of water (up to $3 \mathrm{dm}^{3}$ per day) and nutrients, e.g. tomato plants loaded with fruits. Therefore, an increase in the absorption surface of roots via the presence of AMF could significantly assist plants.

The presence of mycorrhiza in roots of plants inoculated with AMF and grown on rockwool and coconut coir was proved in our experiment, while non-inoculated plants were virtually devoid of mycorrhiza. In the roots of non-inoculated plant the mean mycorrhizal frequency was less than 1.20 and $3.05 \%$, in the 1 . and 2. periods, respectively. The presence of mycorrhiza in these plants might have resulted from the air-borne transfer of propagules from inoculated plants.

The mycorrhizal frequency in tomato roots inoculated with AMF, regardless of the type of substrate and the level of phosphorus in nutrient solution, amounted to 35.79 and $50.82 \%$ at 82 DAT and 112 DAT, respectively. These values are lower than those presented by Maboko et al. (2013), who obtained $78.2 \%$ colonized roots of tomato plants growing in coconut and $77.7 \%$ growing in sawdust. However, in the experiment conducted by Dasgan et al. (2008) the level of the colonization of tomato roots by arbuscular mycorrhizal fungi in both open (without recirculation) and closed (with recirculation) fertigation systems was about $28 \%$. Cwala et al. (2010) obtained a level of colonization of tomato roots in the range of 14 to $25 \%$ in hydroponic cultivation. The colonization could have been much higher in our experiment, especially in the 1. period, if it had been done at seedlings, since mycorrhiza is much more effective in the young roots of plants (Sohn et al. 2003).

The reason for low levels of root colonization by AMF may be the presence of $\mathrm{P}$ in easily digestible forms in the root zone of plants (Ryan and Graham 2002, Cwala et al. 2010). The link between the degree of root colonization and the content of $\mathrm{P}$ in the soil has been proved in several field experiments (Rehber 2004). Ryan and Graham (2002) suggest that the high digestibility of P limits AMF colonization in the roots of plants, and Hawkins and George (1997) report that the presence of $\mathrm{P}$ in a nutrient solution may result in the reduction or disappearance of root colonization, which was proved in the hydroponic cultivation of wheat, which as a result of pre-inoculation was $67.98 \%$ colonized by Glomus mosseae (Funneliformis mosseae). After four weeks of cultivation in a nutrient solution containing $0.9 \mathrm{mM}$, root colonization was reduced to $10.70 \%$, while at the concentration of $0.01 \mathrm{mM}$ P colonization was still above $60 \%$ $(66.36 \%)$. The effect of a high concentration of $\mathrm{P}$ on the low degree of colonization of plant roots was also demonstrated in the cultivation of peppers (Ikiz et al. 2009), tomatoes (Cwala et al. 2010) and marigold (Schmidt et al. 2010). 
Several reports indicate that, in soils with low mineral content, AMF colonization improves the acquisition of low mobility nutrients, not only P, but also Zn and Cu (Liu et al. 2002, Kaya et al. 2003, Ryan and Angus 2003) as well as improving the transport and absorption of P, Ca and Mg (Liu et al. 2002).

In our experiment, higher mycorrhizal frequency was obtained in roots of plants subjected to inoculation and receiving nutrient solution with a lower content of $P$. In the first period of isolation (82 DAT), the highest mycorrhizal frequency characterized plants grown in coconut, while in the second period (112 DAT) plants grown in rockwool. The substrates used in the experiment belong to two different groups, i.e. mineral and organic, and it was proved that the colonization of plant roots by AMF is possible in such substrates. The condition for the development of mycorrhiza is good oxygenation of the root zone (Hawkins and George 1997). The result of our experiment seems to indicate that rockwool, in which humidity was kept in the range of $65-75 \%$, and Forteco Profit coconut of $30 \%$ of air volume were conducive environments for the development of mycorrhiza.

By increasing the absorption surface of plant root systems, AMF have an impact on the enhanced uptake of water and nutrients (Smith and Read 2008, Piao and Liu 2011). In our experiment, the results did not indicate any significant effect of arbuscular mycorrhizal fungi on the nutritional status of plant expressed as the content of nutrients in leaves, except for the impact on the content of $\mathrm{Cu}$ and $\mathrm{Zn}$. In the experiments carried out by Chen et al. (2003) and Christie et al. (2004), it was proved that AMF can improve the zinc uptake by plants in conditions where this micronutrient is deficient in the soil and they can also 'protect' plants against excessive $\mathrm{Zn}$ uptake in $\mathrm{Zn}$-contaminated soils. On the other hand, Watts-Williams and Cavagnaro (2012) did not prove any differences in Zn content in tomato shoots between plants colonized by AMF and those not subjected to mycorrhization (genotype rmc; reduced mycorrhizal colonization) in diverse conditions of this compound in the soil. In our experiment, inoculated plants accumulated significantly less $\mathrm{Zn}$ and $\mathrm{Cu}$ in leaves compared to non-inoculated plants. Throughout the whole period of cultivation, tomato plants received the nutrient solution with the optimum concentration of $\mathrm{Zn}$ and $\mathrm{Cu}$. In soilless cultures, this usually leads to increasing the concentrations of minerals in the root zone of plants, the intensity of which depends mainly on external conditions affecting plant transpiration. It can be assumed that the limiting effect of AMF on uptake by mycorrhized plants $\mathrm{Zn}$ and Cu was the result of elevated concentrations of these components in the root zone. The AMF surface area is an adsorptive site for heavy metal cations and it prevents the entry of toxic metal ions into the roots (Joner et al. 2000). Christie et al. (2004) found that Glomus mosseae (Funneliformis mosseae) tissues bound more than $3 \%$ of Zn (in dry matter) and by this means limited Zn phytotoxicity.

Similar to our study, Dasgan et al. (2008) and Maboko et al. (2013) did not prove any higher nutrient uptake by plants subjected to inoculation with AMF compared to non-inoculated plants. In the cases of $\mathrm{Zn}$ and $\mathrm{Cu}$, we observed a reduction of these compounds. The limited effect of mycorrhiza on nutrient uptake by plants may result from the low intensity of arbuscules. Arbuscules are bushy branched ends of AMF hyphae that grow in the cells of the roots of mycorrhized plants and mediate metabolic exchange between the symbiotic fungus and the plant host (Głuszek et al. 2008, Parniske 2008, Wells and Varel 2011). The low level of intensity of arbuscules means that there is no exchange of substances between the plant and the fungus, which can reduce the benefits of mycorrhizae, including the improvement of the nutritional status of plants. In this experiment, the relative abundance of arbuscules $(\mathrm{A})$ was at a very low level and amounted to 0.02 and $0.07 \%$ in non-inoculated plants and 1.01 and $2.51 \%$ in plants subjected to inoculation, respectively in 1 . and 2. period of roots isolation. The low level of development of arbuscules may also be the reason for the limited impact of mycorrhizal fungi on plant yield. Similar results were obtained by Maboko et al. (2013), who did not observe any benefits of mycorrhizae in terms of the yield or fruit quality of tomatoes, which is explained by the presence in the growing media of such elements as sawdust and coir, phenolics, lignin and other organic compounds that could reduce the development of mycorrhizal structures, despite there being a high mycorrhizal frequency (77.7 - 78.2\%). However, Dasgan et al. (2008) obtained a higher yield from tomato plants inoculated with AMF compared to non-inoculated plants, despite the lack of the effect of AMF on nutritional status. The authors suggest that the reason for this was the fact that, inoculated tomato plants could effectively use photo assimilates for fruit production instead of vegetative growing.

$P$ is an essential element for proper yielding plants. Under the conditions of a deficiency of this macroelement, plants produce less fruit (Sanchez 2007). In the present study, a significantly lower yield was obtained from plants receiving nutrient solution with reduced phosphorus content, which confirmed the lack of benefit of mycorrhiza in the nutrition of tomatoes with this element. Despite the demonstration of mycorrhiza in plant roots (mycorrhizal frequency), it seems that the decisive role was played by the creation of few arbuscules. 
In our experiment, AMF inoculation of plant roots had a limited effect on the quality of fruits. However, it proved the higher concentration of ascorbic acid and total soluble sugars in tomato fruit which was similarly found by Subramanian et al. (2006). Higher P level in a nutrient solution significantly lowered fruit quality shown by lower content of dry matter, ascorbic acid and amino acids. The differences in fruit quality between $\mathrm{P}$ levels in nutrient solution come from inoculated plants (significant interaction between $\mathrm{P}$ level in nutrient solution and mycorrhiza). Fruits from inoculated plants fed nutrient solution with lower P level contained more dry matter and ascorbic acid.

\section{Conclusions}

In conclusion it can be stated that in soilless cultures the colonization of tomato plant roots by AMF is more efficient if the $\mathrm{P}$ content in the nutrient solution is low, i.e. $15 \mathrm{mg} \mathrm{dm}^{-3}$. Colonization is possible, regardless of the type of substrate. However, with longer root symbiosis with AMF, the better conditions for the development of mycorrhiza are created by rockwool.

The fact of root colonization by AMF does not necessarily lead to its significant impact on the yield and quality of tomato fruits, or the nutritional status of plants in soilless cultures with fertigation. Further studies are needed to elucidate the causes of this phenomenon and demonstrate that there is a relationship with soilless cultivation systems.

\section{Acknowledgments}

The study was financed by the National Science Centre within the Project No. N N310 725040 . The authors would like to thank Ewa Muszyńska for her help in preparing microscope slides.

\section{References}

Al-Karaki, G.N. 2006. Nursery inoculation of tomato with arbuscular mycorrhizal fungi and subsequent performance under irrigation with saline water. Scientia Horticulturae 109: 1-7.

Brundrett, M. 1991. Mycorrhizas in Natural Ecosystems. In: Begon, M, Fitter, A.H. \& Macfadyen, A. (eds.). Advances in Ecological Research 21. p. 171-313.

Chen, B.D., Li, X.L., Tao, H.Q., Christie, P. \& Wong, M.H. 2003. The role of arbuscular mycorrhiza in zinc uptake by red clover growing in calcareous soil spiked with various quantities of zinc. Chemosphere 50: 839-846.

Christie, P., Li, X. \& Chen, B.D. 2004. Arbuscular mycorrhiza can depress translocation of zinc to shoots of host plants in soils moderately polluted with zinc. Plant and Soil 261: 209-217.

Colla, G., Rouphael, Y., Cardarelli, M., Tullio, M., Rivera, C.M. \& Rea, E. 2008. Alleviation of salt stress by arbuscular mycorrhizal in zucchini plants growth at low and high phosphorus concentration. Biology and Fertility of Soils 44: 501-509.

Cwala, Y., Laubscher, C.P., Ndakidemi, P.A. \& Meyer, A.H. 2010. Mycorrhizal root colonization and the subsequent host plant response of soil less grown tomato plants in the presence and absence of the mycorrhizal stimulant, Mycotech. African Journal of Microbiology Research 4: 414-419.

Dasgan, H.Y., Kusvuran, S. \& Ortas, I. 2008. Response of soilless grown tomato plants to arbuscular mycorrhizal fungal (Glomus fasciculatum) colonization in re-cycling and open system. African Journal of Biotechnology 7: 3606-3613.

Gianinazzi, S. \& Gianinazzi-Pearson, V. 1986. Progress and headaches in endomycorrhiza biotechnology. Symbiosis 2: 139-149.

Głuszek, S., Sas-Paszt, L., Sumorok, B. \& Derkowska, E. 2008. Wpływ mikoryzy na wzrost, plonowanie roślin ogrodniczych. Postępy Nauk Rolniczych 6: 11-22. (in Polish).

Hawkins, H.J. \& George, E. 1997. Hydroponic culture of the mycorrhizal fungus Glomus mosseae with Linum usitatissimum L., Sorghum bicolor L., and Triticum aestivum L.. Plant and Soil 196: 143-149.

Ikiz, O., Abak, K., Dasgan, H.Y. \& Ortas, I. 2009. Effects of mycorrhizal inoculation in soilless culture on pepper plant growth. Acta Horticulturae 807: 533-540.

Joner, E.J, Briones, R. \& Leyval, C. 2000. Metal binding capacity of arbuscular mycorrhizal mycelium. Plant and Soil 226: 227-234.

Karagiannidis, N., Nikolaou, N., Ipsilantis, I. \& Zioziou, E. 2007. Effects of different N fertilizers on the activity of Glomus mosseae and on grapevine nutrition and berry composition. Mycorrhiza 18: 43-50.

Karandashov, V. \& Bucher, M. 2005. Symbiotic phosphate transport in arbuscular mycorrhizas. Trends in Plant Science 10: 22-29.

Kaya, C., Higgs, D., Kirnak, H. \& Tas, I. 2003. Mycorrhizal colonization improves fruit yield and water use efficiency in water melon (Citrullus lanatus Thunb) grown under well - watered and water-stressed conditions. Plant and Soil 253: 287-292.

Krełowska-Kułas, M. 1993. Badania jakości produktów spożywczych. PWE, Warszawa. 558 p. (in Polish). 
Liu, A., Hamel, C., Elmi, A., Costa, C., Ma, B. \& Smith, D.L. 2002. Concentrations of K, Ca and Mg in maize colonised by arbuscular mycorrhizal fungi under field conditions. Canadian Journal of Soil Science 82: 272-278.

Maboko, M.M., Bertling, I. \& Du Plooy, C.P. 2013. Arbuscular mycorrhiza has limited effects on yield and quality of tomatoes grown under soilless cultivation. Acta Agriculturae Scandinavica, Section B-Soil and Plant Science 63: 261-270.

Mueller, A., Franken, P. \& Schwarz, D. 2009. Nutrient uptake and fruit quality of tomato colonized with mycorrhizal fungus Glomus mosseae (BEG 12) under deficient supply of nitrogen and phosphorus. Acta Horticulturae 807: 383-388.

Parniske, M. 2008. Arbuscular mycorrhiza: the mother of plant root endosymbioses. Nature Reviews Microbiology 6: 763-775.

Pasławski, P. \& Migaszewski, Z.M., 2006. The quality of element determinations in plant materials by instrumental methods. Polish Journal Environmental Studies 15: 154-164.

Persson, J.A. \& Wennerholm, M. 1999. Poradnik mineralizacji Kjeldahl'a. Labconsult, Warszawa. (in Polish).

Phillips, J.M. \& Hayman, D.S. 1970. Improved procedures for clearing roots and staining parasitic and vesicular - arbuscular mycorrhizal fungi for rapid assessment of infection. Transactions of the British Mycological Society 55: 158-161.

Piao, H.C. \& Liu, C.Q. 2011. Variations in nitrogen, zinc, and sugar concentrations in Chinese fir seedlings grown on shrubland and plowed soils inresponse to arbuscular mycorrhizae-mediated process. Biology and Fertility of Soils 47: 721-727.

Pijanowski, E., Mrożewski, S., Horubała, A. \& Jarczyk, A. 1973. Technologia produktów owocowych i warzywnych. PWRiL, Warszawa. 634 p. (in Polish).

Rehber, Y. 2004. The effectiveness of vesicular arbuscular mycorrhizas in soilless culture of muskmelon. MSc thesis. Code number: 2365. Department of Horticulturae, Institute of Natural and Spplied Sciences, University of Cukurova, Adana-Turkey.

Ryan, M.H. \& Angus, J.F. 2003. Arbuscular mycorrhizae in wheat and field pea crops on a low P soil: increased Zn-uptake but no increase in P-uptake or yield. Plant and Soil 250: 225-239.

Ryan, M.H. \& Graham, J.H. 2002. Is there a role for arbuscular mycorrhizal fungi in production agriculture? Plant and Soil 244: 263-271.

Sanchez, C.A. 2007. Phosphorus. In: Barker, A.V., Pilbeam, D.J. (eds.) Handbook of plant nutrition. Taylor \& Francis Group, Boca Raton. p. 51-90.

Schmidt, B., Domonkos, M., Sumalan, R. \& Biro, B. 2010. Suppression of arbuscular mycorrhiza's development by high concentrations of phosphorus at Tagetes patula L. Research Journal of Agricultural Science 42: 156-162.

Schroeder, M.S. \& Janos, D.P. 2004. Phosphorus and intraspecific density alter plant response to arbuscular mycorrhizas. Plant and Soil 264: 335-348.

Smith, S.E. \& Read, D. J. 2008. Mycorrhizal symbiosis, 3rd ed. Elsevier, New York. 769 p.

Subramanian, K.S., Santhanakrishnan, P. \& Balasubramanian, P. 2006. Responses of field grown tomato plants to arbuscular mycorrhizal fungal colonization under varying intensities of drought stress. Scientia Horticulturae 107: $245-253$.

Sohn, B.K., Kim, K.Y., Chung, S.J., Kim, W.S., Park, S.M., Kang, J.G., Rim, Y.S., Cho, J.S., Kim, T.H. \& Lee, J.H. 2003. Effect of the different timing of AMF inoculation on plant growth and flower quality of chrysanthemum. Scientia Horticulturae 98: $173-183$.

Sylvia, D.M., Alagely, A.K., Chellemi, D.O. \& Demchenko, L.W. 2001. Arbuscular mycorrhizal fungi influence tomato competition with bahiagrass. Biology and Fertility of Soils 34: 448-452.

Trouvelot, A., Kough, J.L. \& Gianinazzi-Pearson, V. 1986. Mesure du taux de mycorrhization VA d'un systeme radiculaire. Recherche de methods d'estimation ayant une signification fonctionnelle. In: Gianinazzi-Pearson, V., Gianinazzi, S. (eds.). Physiological and genetical aspects of mycorrhizae, Paris, INRA. p. 217-221.

Turnau, K., Jurkiewicz, A. \& Grzybowska, B. 2002. Rola mikoryzy w bioremediacji terenów zanieczyszczonych. Kosmos. Problemy Nauk Biologicznych 2: 185-194. (in Polish).

Watts-Williams, S.J. \& Cavagnaro, T.R. 2012. Arbuscular mycorrhizas modify tomato responses to soil zinc and phosphorus addition. Biology and Fertility of Soils 48: 285-294.

Wells, J. \& Varel, V. 2011. Symbioses of plants, animals and microbes. In: Pond W.G., Bazer, F.W. \& Rollin, B.E. (eds.) Animal Welfare in Animal Agriculture: Husbandry, Stewardship and Sustainability in Animal Production. CRC Press, New York. p.185-203.

Wu, Q.S. \& Zou, Y.N. 2010. Beneficial roles of arbuscular mycorrhizas in citrus seedlings at temperature stress. Scientia Horticulturae 125: 289-293.

Yemm, E.W. \& Willis, A.J. 1954. The estimation of carbohydrates in plant extracts by anthrone. Biochemical Journal 57: $508-514$.

Zhu, X.Q., Wang, C.Y., Chen, H. \& Tang, M. 2014. Effects of arbuscular mycorrhizal fungi on photosynthesis, carbon content, and calorific value of black locust seedlings. Photosynthetica 52: 247-252. 